\title{
PENGARUH BLENDING MINYAK NABATI PADA PELUMAS DARI MINYAK MINERAL TERHADAP STABILITAS OKSIDASI DAN KETAHANAN KOROSI LOGAM
}

\author{
Tita Diana Ningsih" ${ }^{1)}$, Retno Farida ${ }^{2)}$ Ratri Ariatmi Nugrahani ${ }^{3)}$ \\ ${ }^{1}$ Jurusan Teknik Kimia Universitas Muhammadiyah Jakarta \\ titadiana20@gmail.com
}

\begin{abstract}
Lubricant is a material used to coat the surface so it can be separated from other surfaces that do motion relative to the other surface. Various attempts were made to reduce the use of lubricants derived from mineral oils, where availability is limited, nonrenewable also has the disadvantage of which are not degraded so may result in environmental pollution. One effort that can be done to reduce the use and improve the characteristics of mineral oil is by blending the base oil of mineral oil with vegetable oil. The purpose of this research was to study the effect of the addition of vegetable oil in the base oil of mineral oil against oxidation stability. Oxidation stability in terms of physical and chemical properties of lubricants, namely Total Acid Number (TAN), viscosity index (IV), and test its resistance to corrosion. The method used in this research is by mixing mineral oil base oil with a mixture of coconut oil and rice bran oil in order to increase its quality. Vegetable oil is added to the base oil mineral oil in this study was $0 \%, 5 \%, 10 \%, 15 \%$, and $20 \%(\% \mathrm{v} / \mathrm{v})$, then do the blending for 15 minutes at a temperature of $600 \mathrm{C}$ to $700 \mathrm{C}$ and allowed to stand for 30 days. Further testing its effect on Total Acid Number, Viscosity Index, and Heavy Metal Reduction.
\end{abstract}

Keywords: Base Oil, Vegetable Oil, Oxidation Stability

ABSTRAK. Pelumas adalah bahan yang dipakai untuk melapisi permukaan sehingga tidak kontak langsung dengan permukaan lain yang bergerak relatif terhadap permukaan lain. Beberapa usaha telah dilakukan untuk meminimalkan pemakaian pelumas dari minyak bumi, karena terbatasnya ketersediaan, tidak terbarukan dan mempunyai kelemahan diantaranya tidak mampu didegradasi sehingga bisa mengakibatkan pencemaran lingkungan. Salah satu usaha yang bisa dilakukan untuk menurunkan konsumsi dan meningkatkan karakteristik minyak bumi adalah dengan mencampurkan antara base oil dari minyak mineral dengan minyak nabati. Tujuan penelitian ini adalah untuk mempelajari pengaruh pencampuran minyak nabati pada base oil dari minyak mineral terhadap kestabilan oksidasi. Kestabilan oksidasi dikaji berdasarkan sifat fisik dan kimianya, yaitu Total Acid Number (TAN), Indek Viskositas (IV), dan Uji ketahanan terhadap korosi. Penelitian dilakukan dengan mencampurkan base oil minyak mineral dengan campuran minyak kelapa dan minyak dedak padi agar kualitasnya meningkat. Minyak nabati yang ditambahkan terhadap base oil minyak mineral pada penelitian ini adalah 0\%, 5\%, 10\%, 15\%, serta 20\% (\%v/v), pencampuran dilakukan selama 15 menit pada temperatur $60^{\circ} \mathrm{C}$ sampai dengan $70^{\circ} \mathrm{C}$. Campuran minyak didiamkan selama 30 hari, selanjutnya diuji Total Acid Number, Indeks Viskositas, dan Pengurangan Berat Logam

Kata Kunci: Base Oil, Minyak Nabati, Stabilitas Oksidasi 


\section{Bahan dan Alat}

\section{PENDAHULUAN}

Konsumsi pelumas di Indonesia bertambah 1,8 \% dari tahun 2010 ke tahun 2014 (Badan Pusat Statistik, 2014). Konsumsi pelumas meningkat sebanding peningkatan industri otomotif. Oleh karena itu, maka berkembang produk ramah lingkungan yang mampu mensubstitusi minyak mineral sebagai base oil pelumas dengan cara mencampurkannya dengan bahan nabati. Hal ini di dasari oleh tersedianya bahan baku nabati di Indonesia, seperti minyak kelapa, minyak kelapa sawit, minyak dedak padi yang merupakan limbah dari pengolahan padi.

Base Oil pelumas bisa bersumber dari minyak mineral dan turunannya, minyak sintetis, minyak nabati dan minyak sintetis turunan minyak nabati. Minyak mineral tidak terbarukan, maka minyak nabati dapat dijadikan alternatif sebagai base oil dengan harga murah, bisa didegradasi dan terbarukan (Honary, 2011).

Berdasarkan penelitian Talkit dkk, 2012 penambahan minyak nabati pada minyak bumi adalah usaha untuk memperbaiki sifat pelumasan sehingga bisa dapat mensubstitusi penggunaan minyak bumi.

Salah satu parameter yang dijadikan ukuran produk pelumas adalah stabilitas Oksidasi. Stabilitas oksidasi adalah kemampuan pelumas untuk mempertahankan oksidasi dengan menggunakan beberapa parameter ukuran, seperti Total Acid Number (TAN) dan Indeks Viskositas (IV) (Karina, 2010). Uji Ketahanan Korosi dapat dilakukan dengan menghitung kehilangan berat logam yang dicelupkan di dalam larutan korosif (Aini, 2012). Rendahnya stabilitas oksidasi dapat berakibat pada terjadinya korosi. Pada penelitian ini akan dikaji performa blending minyak nabati pada base oil minyak mineral dalam meningkatkan kestabilan oksidasi dan potensinya untuk mengurangi konsumsi minyak mineral.

\section{METODOLOGI PENELITIAN}

\section{Bahan}

Bahan yang digunakan untuk proses adalah minyak mineral (Evalube Base Oil, High Viscosity Index), minyak nabati, yaitu minyak kelapa, minyak dedak padi, etanol pa, $\mathrm{KOH} 0.1 \mathrm{~N}$, air dan sampel besi baja.

\section{Alat}

Beberapa alat yang dipakai di dalam penelitian ini adalah magnetic stirrer, pemanas, Termometer, Buret, Beaker glass, timbangan, alat uji SEM (Scanning Electron Microscopy) dan alat uji EDX (Energy Dispersion X-ray Spectroscopy)

\section{Metode Penelitian}

\section{Prosedur Penelitian}

Penelitian mengikuti Diagram Alir penelitian seperti pada Gambar 1 .

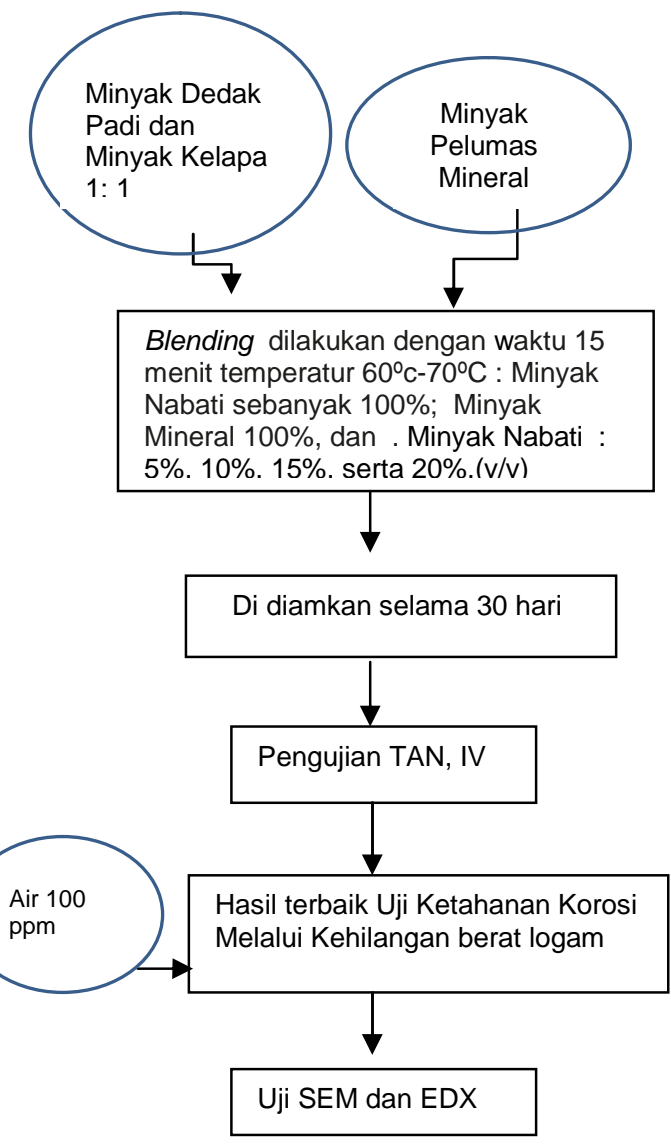

Gambar 1. Prosedur Blending Minyak nabati dan base oil minyak mineral dan pengujiannya 


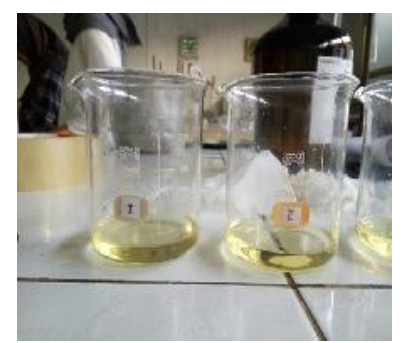

Gambar 2. Sampel larutan blending base oil.

Gambar 2. menunjukkan gambar sampel larutan blending minyak nabati dan pelumas minyak mineral.

\section{Metoda Pengujian}

1. Uji Kestabilan Oksidasi (ASTM D943)

Campuran hasil blending didiamkan selama 30 hari selanjutnya diuji Bilangan Asam (TAN) dan Indeks Viskositas (IV).

\section{Total Acid Number (TAN)}

Timbang $\pm 2,5$ gram sampel pelumas dalam beaker $100 \mathrm{~mL}$, Tambahkan 25 $\mathrm{mL}$ Etanol PA dan 3-5 tetes indikator fenolftalein (pp), Titrasi dengan menggunakan penitar $\mathrm{KOH} 0,1 \mathrm{~N}$.

3. Uji Ketahanan terhadap Korosi

Tahapan yang dilakukan dalam uji ketahanan terhadap korosi: pembuatan larutan korosi pelumas dicampur dengan air sebanyak 100 ppm. Sampel baja dimasukkan ke dalam larutan campuran selama 30 hari pada suhu kamar. Selanjutnya sampel dibersihkan dan dikeringkan di dalam oven. Korosi yang terjadi dianalisis dengan menghitung kehilangan massa,

\section{Uji Permukaan Logam}

SEM (Scanning Electron Microscopy) adalah pengujian untuk mengetahui morfologi. SEM - EDX (Scanning Electron Microscopy - Energy Dispersion $X$-ray Spectroscopy) digunakan untuk megetahui daerah korosi dan mengamati komposisi kimianya secara kualitatif dan semi kuantitatif

HASIL PENELITIAN DAN PEMBAHASAN

\section{Hasil Uji TAN}

Hasil Uji Bilangan Asam (TAN) mula-mula dan setelah didiamkan selama 30 hari, dapat dilihat pada Tabel 1

Tabel 1 . Hasil Pengujian Bilangan Asam (TAN)

\begin{tabular}{|r|r|r|r|r|r|}
\hline $\begin{array}{c}\text { Minyak } \\
\text { Mineral } \\
(\mathrm{mL})\end{array}$ & $\begin{array}{c}\text { Minyak } \\
\text { Kelapa } \\
(\mathrm{mL})\end{array}$ & $\begin{array}{c}\text { Minyak } \\
\text { Dedak } \\
\text { Padi } \\
(\mathrm{mL})\end{array}$ & $\begin{array}{c}\text { TAN } \\
\text { sebelum } \\
30 \text { hari } \\
\mathrm{mg} \\
\mathrm{KOH} / \mathrm{g} \\
\mathrm{minyak}\end{array}$ & $\begin{array}{c}\text { TAN } \\
\text { Setelah } \\
30 \mathrm{hari} \\
\mathrm{mg} \\
\mathrm{KOH} / \mathrm{g} \\
\mathrm{minyak}\end{array}$ & $\begin{array}{c}\text { perub } \\
\text { ahan }\end{array}$ \\
\hline 50,00 & 0,00 & 0,00 & 0,25 & 0,25 & 0,00 \\
\hline 47,50 & 1,25 & 1,25 & 0,20 & 0,20 & 0,00 \\
\hline 45,00 & 3,75 & 3,75 & 0,30 & 0,32 & 0,02 \\
\hline 40,00 & 5,00 & 5,00 & 0,30 & 0,35 & 0,05 \\
\hline 0,00 & 25,00 & 25,00 & 0,30 & 0,35 & 0,05 \\
\hline
\end{tabular}

Pemılınan mınyak kelapa dılakukan dengan alasan pemilihan karena mayoritas mengandung asam lemak jenuh (C12:0, Asam Laurat dan C14:0, Asam Miristat) (Kumar and Kishna, 2015) sehingga cenderung memiliki stabilitas oksidasi tinggi. Kandungan asam laurat memiliki sifat juga sebagai antioksidan alami. Pemilihan minyak dedak padi adalah berdasarkan ketersediaannya sebagai hasil samping pengolahan padi, sehingga diharapkan akan memiliki nilai tambah jika digunakan sebagai campuran pelumas minyak mineral. Tabel 1 menunjukkan bahwa dengan semakin besarnya penambahan minyak nabati, yaitu campuran maka menunjukkan perubahan TAN yang semakin besar dan selanjutnya konstan, hal ini disebabkan karena minyak dedak padi yang ditambahkan mengandung ikatan rangkap pada rantai karbon senyawa trigliserida dalam minyak nabati. yang berpotensi mengakibatkan terjadinya reaksi oksidasi, sehingga hal ini dapat berakibat naiknya TAN. Selanjutnya kurva pada

Gambar 3 menunjukkan hubungan antara konsentrasi minyak nabati terhadap perubahan TAN 


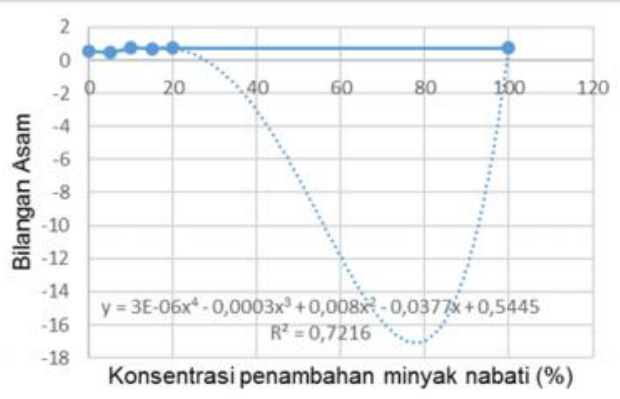

Gambar 3. Kurva Hubungan Konsentrasi dengan Uji TAN (Bilangan Asam)

Gambar 3 menunjukkan dengan adanya penambahan minyak nabati pada pelumas mineral akan dapat mempengaruhi besarnya TAN. Dengan $R^{2}=0,7216$, mendekati 1, menunjukkan adanya korelasi yang kuat antara penambahan minyak nabati pada minyak mineral terhadap TAN.

\section{Hasil Uji Indeks Viskositas}

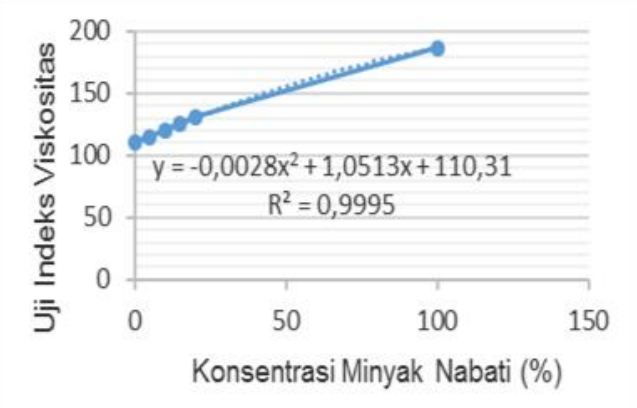

Gambar 4. Kurva Hubungan Konsentrasi dengan Indek Viskositas

Berdasarkan pada Gambar 4 terlihat bahwa dengan semakin besarnya konsentrasi minyak nabati yang ditambahkan, maka Indeks Viskositas semakin besar, hal ini menunjukkan bahwa semakin tinggi indeks viskositasnya maka oksidasi semakin rendah. Penambahan minyak nabati pada pelumas mineral akan dapat mempengaruhi besarnya indeks viskositas. Dengan $R^{2}=$ 0,9995, mendekati 1, menunjukkan adanya korelasi yang kuat antara penambahan minyak nabati pada minyak mineral terhadap indeks viskositas.

\section{Hasil Uji Pengurangan Berat Logam}

Hasil uji pengurangan berat logam setelah direndam dalam larutan blending dengan konsentrasi minyak nabati $20 \%$ (Tabel 2).

Tabel 2. Pengukuran massa Logam direndam dalam larutan blending dengan konsentrasi minyak nabati $20 \%$ (v/v)

\begin{tabular}{c|c|c}
\hline $\begin{array}{c}\text { Waktu } \\
\begin{array}{c}\text { Perendaman, } \\
\text { hari }\end{array}\end{array}$ & $\begin{array}{c}\text { Berat } \\
\text { sampel 1 } \\
(\mathrm{g})\end{array}$ & $\begin{array}{c}\text { Berat } \\
\text { sampel } 2 \\
(\mathrm{~g})\end{array}$ \\
\hline 0 & 55,00 & 60,20 \\
\hline 10 & 54,78 & 60,00 \\
\hline $\begin{array}{c}\text { Pengurangan } \\
\text { berat sampel }\end{array}$ & $0,40 \%$ & $0,33 \%$ \\
\hline
\end{tabular}

Tabel 2 menunjukkan pengurangan berat logam setelah direndam di dalam larutan blending dengan konsentrasi minyak nabati $20 \%(\mathrm{v} / \mathrm{v})$ selama 10 hari, sampel 1 dan 2 menunjukkan pengurangan berat yang hampir sama, dengan rata-rata 99,6\%.

\section{Uji Permukaan SEM dan EDX}

hasil uji SEM dan EDX pada sampel logam sesudah direndam ditunjukkan pada Gambar 5.

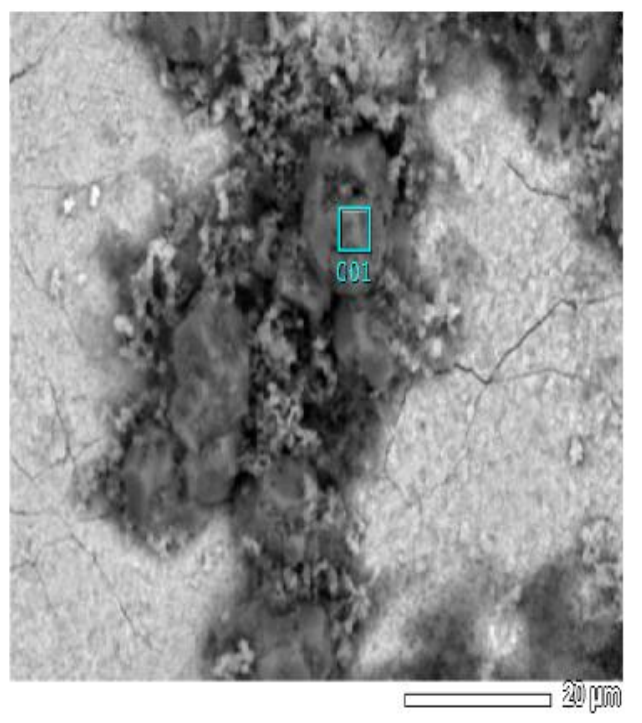




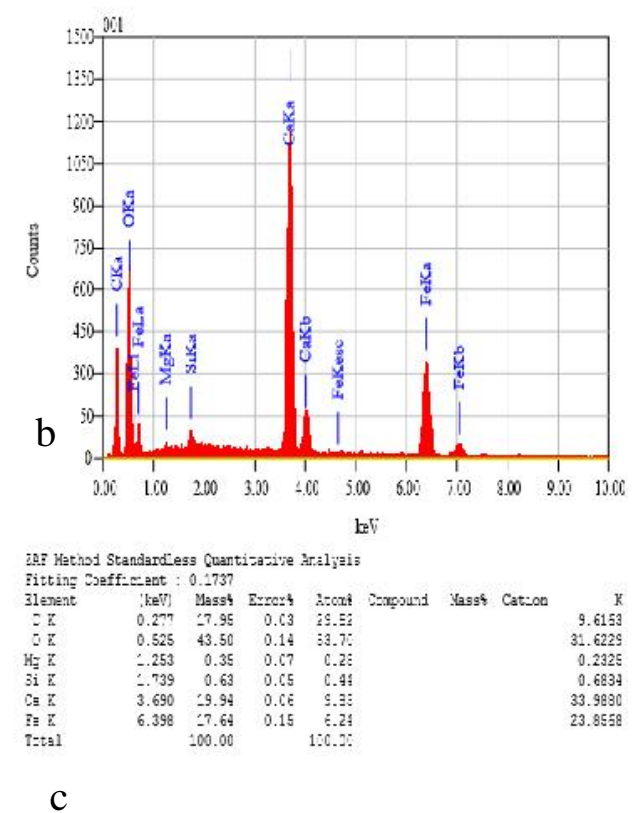

Gambar 5, Hasil Uji SEM dan EDX

Gambar 5. menunjukkan Morfologi serangan korosi pada sampel konsentrasi air 100 ppm dengan perendaman selama 3 hari.

Gambar 5a. menunjukkan produk korosi karena pengaruh unsur korosif air. Gambar ini menunjukkan bahwa permukaan logam basah mengakibatkan sedikitnya oksigen terkandung pada elektrolit di sekitarnya. Akibatnya semakin panjang lintasan yang dilalui oleh oksigen untuk menuju logam, maka daerah ini berlaku sebagai anoda. Akibatnya terjadi pelarutan logam yang menyebabkan pengendapan produk korosi di sekitar lubang sumuran, sehingga membentuk karat (Aini, 2012). Gambar 5b merupakan puncak spektrum EDX yang menunjukkan adanya produk korosi $\mathrm{FeO}$. Gambar 5c menunjukkan hasil pengujian globular daerah terkorosi.

\section{KESIMPULAN (DAN SARAN)}

\section{Kesimpulan}

Hasil Uji Bilangan Asam dan Uji Indeks Viskositas komposisi blending pelumas terbaik adalah penambahan konsentrasi minyak nabati sebanyak $20 \%$, hal ini ditandai perubahan TAN dan IV yang cukup rendah. Pengurangan berat logam yang telah direndam dalam blending pelumas dengan minyak nabati $20 \%$ cukup rendah. Pengurangan berat logam menunjukkan adanya yang terkorosi, seperti yang ditunjukkan dari hasil uji permukaan logam.

\section{Ucapan Terimakasih}

Ucapan terimakasih disampaikan kepada Kemenristekdikti atas dana Hibah PKM-P 2015 yang telah diterima untuk berjalannya penelitian ini

\section{DAFTAR PUSTAKA}

Abdulbari, H.A., Rosli, M.Y., Abdurrahman H.N., Nizam, M.K., 2011, Lubricating Grease from spent bleaching carth and waste cooking oil : Tribology Properties, International Journal of the Physical Science, Vol 6 (20), 4695-4699.

Aini, N. dan Triwikantoro, Pengaruh Konsentrasi Air dalam Pelumas terhadap Sifat Korosi Baja Karbon ST 37, http://digilib.its.ac.id/public/lTSUndergraduate-23787-Paper 856382.pdf

Alice, Aby,2011,Analisa Pelumas Mesin, http://aby-

alice.blogspot.co.id/2011/12/analisapelumas-mesin.html

Darmanto, 2011, Mengenal Pelumas dalam Mesin, Vol 7. No 1. April 2011. hlm 5-10.

Dermawan, D., Pertiwi, D.S., Siddik, A., Pahlevi, S.R., 2011, Pengembangan Minyak Lumas Biobased Formulasi dengan Ashless Antiwear Agent, Prosiding Seminar Rekayasa Kimia dan Proses, ISSN : 1411-4216

Honary, L.A, James, W., 2011, Performance Properties of Biobased Rail Curve Grease, Seminar Proceeding, Minneapolis

Karina, R.M., Yuliani, C. 2010. Kompatibilitas Campuran Minyak Lumas Dasar Jenis Mineral dengan 
Minyak Nabati sebagai Minyak

Lumas Dasar Pelumas Mesin

Kendaraan Bermotor., Lembaran

Publikasi Lemigas, 44 (3).

Kim K., 2012, Epoxidation of Vegetables Oils Using the Heterogeneous Catalysis, Amorphous Ti-SiO2, Disertation Institute of Chemical Thecnology and Heterogeneous

Krishna Reddy, Naval Kabra, Umesh Kunchum, and T. Vijayakumar, 2014, Experimental Investigation on Usage of Palm Oil as a Lubricant to Substitute Mineral Oil in Cl Engines, India

Kumar, P.P.K and Kishna A.G.G., 2015. Physicochemical characteristics of commercial coconut oils produced in India. Grasas Y Aceites. 66: (1).

Nardi., Uji keausan minyak biji kepoh menggunakan metode four ball wear tes (Dengan pembanding minyak mineral HVI 60 dan minyak jarak), http://lib.ui.ac.id/opac/ui/detail.jsp?id= 20247136\&lokasi=lokal

Nizam, M.K., dan Abdulbari H.A., 2009, The Use of Vegetable Oil in Lubricant as Base Oil : a Review, Proseding National Conference on Postgraduate Research (NCONPGR) Oktober, University Malaysia Pahang.

Nugrahani, R.A., 2007, Perancangan Proses Pembuatan Pelumas Dasar Sintetis Dari Minyak Jarak Pagar (Jatropha curcas L.) melalui Modifikasi Kimiawi, Disertasi Program Doktor, IPB.

Talkit Marotrao, K, 2012 Physiochemical Properties of Oil Blend and Their Effect on Lubrication Properties, EISSN2249-8974 